\title{
Novel Technique of Craniospinal Axis Proton Therapy with the Spot-Scanning System
}

\author{
Avoidance of Patching Multiple Fields and Optimized Ventral Dose Distribution
}

\author{
Beate Timmermann', Antony Jonathan Lomax', Luisa Nobile², Michael Andreas Grotzer ${ }^{3}$, \\ Markus Weiss ${ }^{3}$, Rolf-Dieter Kortmann ${ }^{4}$, Alessandra Bolsi', Gudrun Goitein ${ }^{1}$
}

\begin{abstract}
Background and Purpose: Conventional craniospinal irradiation (CSI) is a complex procedure carrying a high risk of adverse side effects. Still, it is indispensable for cure in a number of pediatric brain tumors. In this study, the feasibility and the potential advantage of spot-scanning proton therapy for CSI are investigated.

Material and Methods: A boy (5.5 years of age) with a recurrent medulloblastoma received CSI with a single posterior field using the spot-scanning system at Paul Scherrer Institute. Dose distribution to the targets and the organs at risk, treatment time, reproducibility of patient positioning, toxicity (according to EORTC/RTOG score), and treatment outcome were evaluated.

Results: The plan achieved a homogeneous coverage of the target volume, even using a single field. The doses to the organs ventral to the target were minimized. During treatment, grade 1 skin reaction and grade 2 central nervous system toxicity were observed. After 2 months, the boy presented with a transitory fatigue. After 24 months, he is alive and free of disease. Growth hormones and thyroid hormones are reduced.

Conclusion: These results, based on a single patient, suggest that spot-scanning proton therapy for craniospinal treatment is feasible and safe. By applying a single dorsal field, difficulties of multiple-field patching can be avoided and the ventral dose spread can be minimized.
\end{abstract}

Key Words: Craniospinal irradiation · Proton radiation therapy

Strahlenther Onkol 2007;183:685-8

DOI 10.1007/s00066-007-1759-1

\begin{abstract}
Innovative Technik zur Behandlung der kraniospinalen Achse mit Spot-Scanning-Protonentherapie. Vermeidung von Feldanschlüssen und Optimierung der ventralen Dosisverteilung
\end{abstract}

Hintergrund und Ziel: Konventionelle Methoden der Bestrahlung der kraniospinalen Achse (CSI) sind kompliziert und beinhalten ein hohes Risiko für Spätfolgen. Dennoch bleibt die CSI für die Heilung einer Reihe von Hirntumoren im Kindesalter unerlässlich. In dieser Studie werden die Durchführbarkeit und potentielle Vorteile der Spot-Scanning-Protonentherapie geprüft.

Material und Methodik: Ein 5,5-jähriger Junge mit Rezidiv eines Medulloblastoms sollte eine CSI erhalten und wurde am Paul Scherrer Institut mit einem einzigen dorsalen Feld am Spot-Scanning-System mit Protonen bestrahlt. Untersucht wurden die Dosisverteilung für Zielvolumina, Risikoorgane, Behandlungszeit, Reproduzierbarkeit der Lagerung, Nebenwirkungen (nach Kriterien der EORTC/RTOG) und Therapieergebnis.

Ergebnisse: Mit dem Therapieplan konnte trotz der Verwendung nur eines Bestrahlungswinkels eine homogene Dosisverteilung für das Zielvolumen erreicht werden. Die applizierte Dosis an den ventral gelegenen Organen war vernachlässigbar. An Akuttoxizitäten wurden lediglich eine Grad-1-Reaktion der Haut und eine Grad-2-Reaktion am zentralen Nervensystem beobachtet. 2 Monate nach Abschluss der Behandlung trat eine vorübergehende Abgeschlagenheit auf. Nach 24-monatiger Beobachtungszeit ist der Junge weiterhin tumorfrei. Wachstums- und Schilddrüsenhormone sind herabgesetzt.

Schlussfolgerung: Die Behandlung erwies sich bei dem beschriebenen Patienten als gut durchführbar und verträglich. Mit der Verwendung eines einzigen dorsalen Feldes konnten Probleme durch Feldanschlüsse vermieden werden, und die Dosis ventral des Zielgebiets wurde minimiert.

Schlüsselwörter: Kraniospinale Bestrahlung · Protonentherapie

\footnotetext{
${ }^{1}$ Center for Proton Radiation Therapy, Paul Scherrer Institute, Villigen, Switzerland,

${ }^{2}$ Children's Hospital, Hospital Locarno, Switzerland,

${ }^{3}$ University Children's Hospital of Zurich, Switzerland,

${ }^{4}$ Department of Radiation Oncology, University of Leipzig, Germany.
}

Received: April 4, 2007; accepted: September 7, 2007 


\section{Introduction}

Craniospinal irradiation (CSI) is important in the care of children with high-risk brain tumors. However, long-term side effects are both frequent and severe $[1,7,12,19]$ depending on age and applied dose [11, 19, 24].

Technical administration of conventional CSI is difficult and time-consuming. Multiple fields and moving of junctions need to be performed routinely. Any deviation in delivering the prescribed dose can result in an increased rate of recurrences $[4,8,14]$.

Recently, several reports on the potential benefit of protons when compared to conventional X-rays in pediatric brain tumors have been published $[6,13,17,27]$.

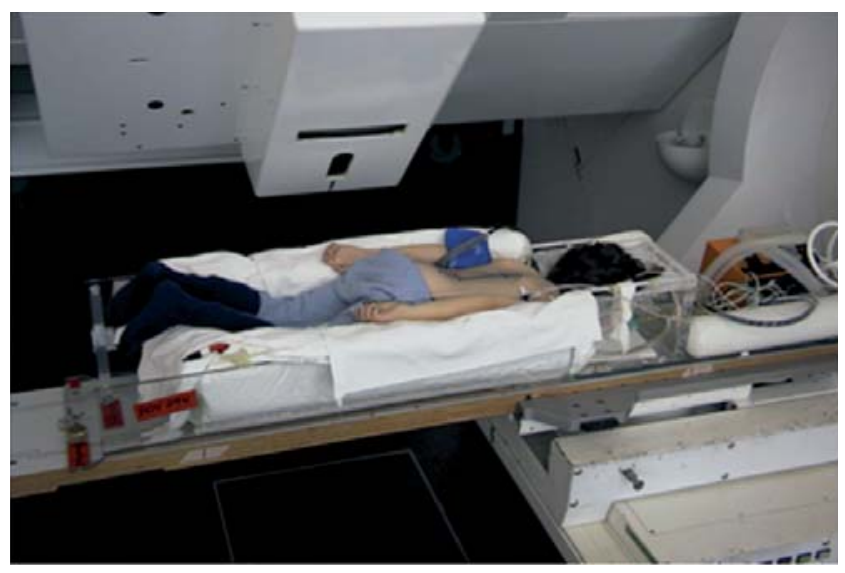

Figure 1. Immobilization of the child in prone position with a vacuum cast and a custom-made face holder.

Abbildung 1. Immobilisation des Kindes in Bauchlage mit Vakuumschale und individuell gefertigter Kopfhalterung.

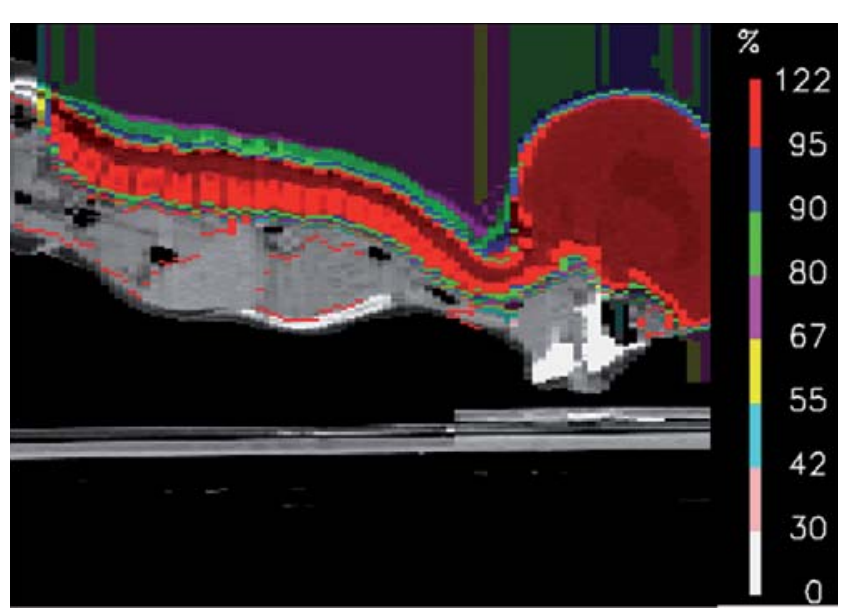

Figure 2. Dose distribution with spot-scanning proton therapy for the craniospinal volume (sagittal CT; thin green line: planning target volume).

Abbildung 2. Dosisverteilung mit Spot-Scanning-Protonentherapie für das kraniospinale Zielvolumen (sagittales CT; feine grüne Linie: Planungszielvolumen).
At the Paul Scherrer Institute (PSI), further developments have been made to administer the first CSI.

\section{Material and Methods}

A 5.5-year-old boy with a recurrent medulloblastoma was referred to PSI. Radiotherapy was prescribed to the neuraxis and the posterior fossa with total doses of $36 \mathrm{~Gy}$ and $54 \mathrm{~Gy}$, respectively $(4 \times 2.0 \mathrm{CGE}$ weekly). During radiotherapy, temozolomide was administered.

For irradiation, the child was immobilized (Figure 1) and computed tomography (CT) was performed for planning.

Target volumes as well as relevant organs at risk were delineated according to the guidelines of the HIT 2000 protocol [15]. First, 18 fractions were given to the craniospinal volume (Figure 2) including the vertebral bodies in order to avoid asymmetric growth of the spine (Figures 3a and 3b). Afterwards, the second plan encompassed the posterior fossa (Figure 4).

Treatment was performed using the spot-scanning technique of proton therapy [21]. This method has already been described in detail elsewhere [18, 22, 25]. As all delivered proton pencil beams are parallel to each other, field patching is unnecessary. Before the delivery of each fraction, accurate patient positioning was achieved through the comparison of anatomic landmarks in the planning topograms and daily orthogonal topograms from a dedicated CT scanner. Translation vector was calculated in three degrees of freedom. In case of rotation, the patient was repositioned.

The absorbed doses for the gonads as well as the thyroid were measured by thermoluminescent dosimeters.

Acute and long-term side effects of treatment were documented according to EORTC/RTOG criteria [3, 5].

\section{Results}

The first series plan consisted of a single field delivered from the posterior aspect to the whole brain and spinal axis. Dose-volume histograms to these organs are shown in Figure 5 .

Time required for positioning procedure ranged from 7 to $12 \mathrm{~min}$. Mean daily table corrections were $0 \mathrm{~mm}$ (range, -2 to $1 \mathrm{~mm}$ ) in the lateral direction, $0 \mathrm{~mm}$ in the posterior-anterior direction (range, -1 to $1.5 \mathrm{~mm}$ ) and $-0.5 \mathrm{~mm}$ along the patient's long axis (range, -3 to $2.5 \mathrm{~mm}$ ).

The median total time to deliver a fraction (including patient setup and imaging) was $35 \mathrm{~min}$ for the CSI. Median times on the treatment machine alone were $21 \mathrm{~min}$ for the CSI and $18 \mathrm{~min}$ for the posterior fossa.

Acute side effects during treatment were mild. Mild skin erythema and epilation (grade 1 reaction) and mild tiredness (Karnofsky 70-80\%) were observed. Additionally, mild nausea was reported and successfully treated with systemic steroids (grade 2 reaction). 2 months after finishing radiotherapy, the boy presented with fatigue and loss of appetite over 4 weeks, which resolved spontaneously. 
Figures $\mathbf{3} a$ and $\mathbf{3 b}$. Dose distribution with spot-scanning proton therapy for the craniospinal volume not encompassing a) the vertebral body and b) modified to encompass the vertebral body, respectively (thin green line: respective planning target volume).

Abbildungen $\mathbf{3} \mathbf{a}$ und $\mathbf{3} \mathbf{b}$. Dosisverteilung mit Spot-Scanning-Protonentherapie für das kraniospinale Zielvolumen a) ohne bzw. b) mit Einschluss des Wirbelkörpers (feine grüne Linie: jeweiliges Planungszielvolumen).

24 months after finishing proton therapy, the boy is still alive and free of disease. He still presents with a mild residual hemiplegia. In the occipital region, a slight hair loss can still be observed (grade 1). Deficit of growth and thyroid hormones was revealed. Regarding the neuropsychological findings, memory is good, whereas visual, motorial and spatial skills are somewhat reduced. Hearing and visual tests are normal. The boy is attending regular school.

\section{Discussion}

CSI still plays a major role in the curative treatment of pediatric medulloblastomas and supratentorial neuroectodermal brain tumors. Unfortunately, there are several well-recognized drawbacks such as severe late effects of treatment especially in very young children. Additionally, the complex technique which is usually performed when irradiating the entire central nervous system (CNS) is time-consuming, and its reliability and reproducibility are extremely fragile. Proton therapy is recognized as a modality carrying the potential of normal tissue sparing due to favorable physical characteristics. Until now, however, only one report on three patients treated with passive scattering proton therapy for the craniospinal volume has been published [28]. At the PSI, the use of spot scanning offers additional advantages for the irradiation of the neuraxis.

With this method we were able to administer a single posterior field which covered the entire CNS. The application of a single field, together with the parallel-beam scanning approach avoids the need to patch divergent fields which always carries the risk for gaps or too much overlapping at the field junctions. It is well documented, that the risk of deviations from the prescribed dose in the CNS might well lead to an increased risk for recurrences or to an increased risk for toxicity in the case of local hot spots $[4,9,10]$.

We would like to point out, that the use of one single beam is unique for the CSI, as conventional photon techniques, despite using modern methods, usually require three to four fields, and passive scattering proton therapy has also been reported to require up to six fields $[20,26,28]$.

Figure 5. Dose-volume histograms (DVHs) to the craniospinal target volume and selected organs at risk. CTV: clinical target volume; PTV: planning target volume.

Abbildung 5. Dosis-Volumen-Histogramme (DVHs) für das kraniospinale Zielvolumen und ausgewählte Risikoorgane. CTV: klinisches Zielvolumen; PTV: Planungszielvolumen.
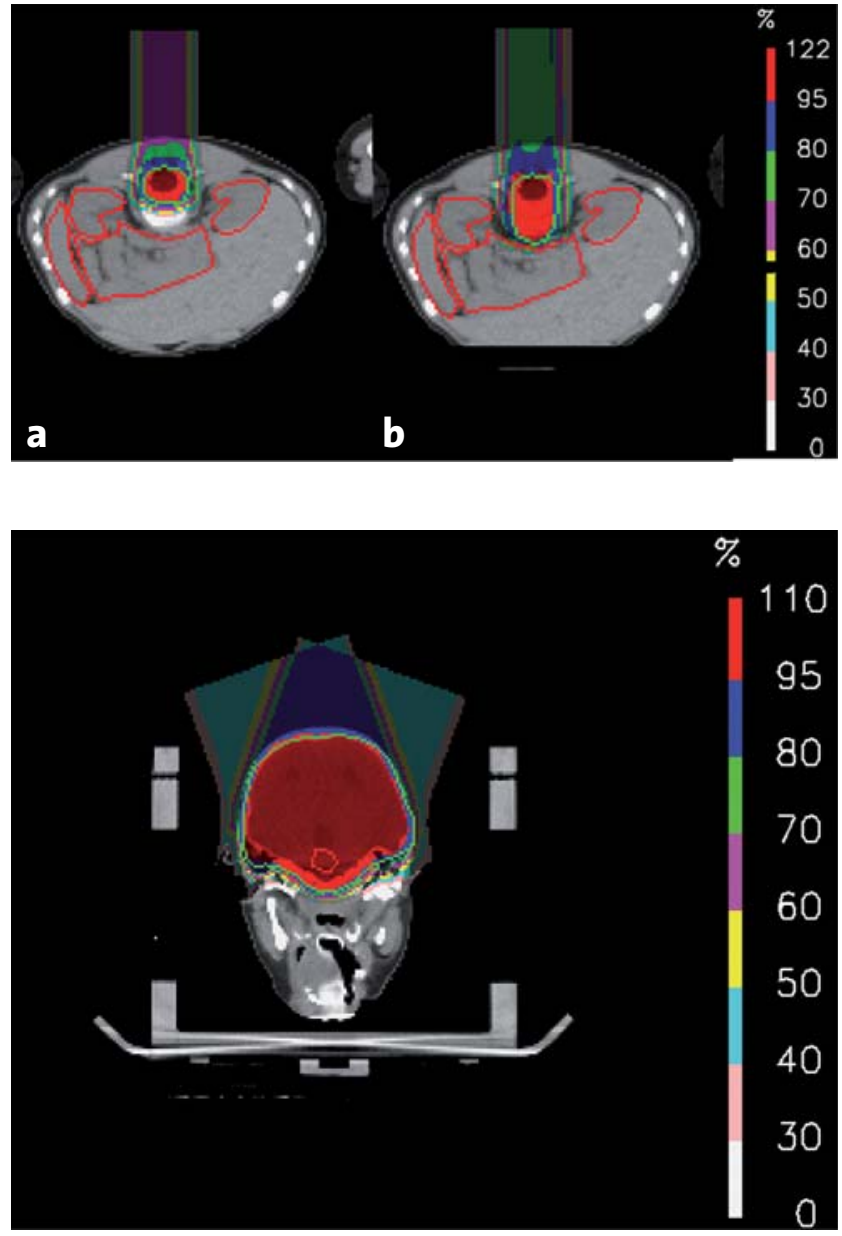

Figure 4. Dose distribution with spot-scanning proton therapy for the posterior fossa volume (axial CT; thin green line: planning target volume).

Abbildung 4. Dosisverteilung mit Spot-Scanning-Protonentherapie für die hintere Schädelgrube (axiales CT; feine grüne Linie: Planungszielvolumen).

DVHs

(first series plan)

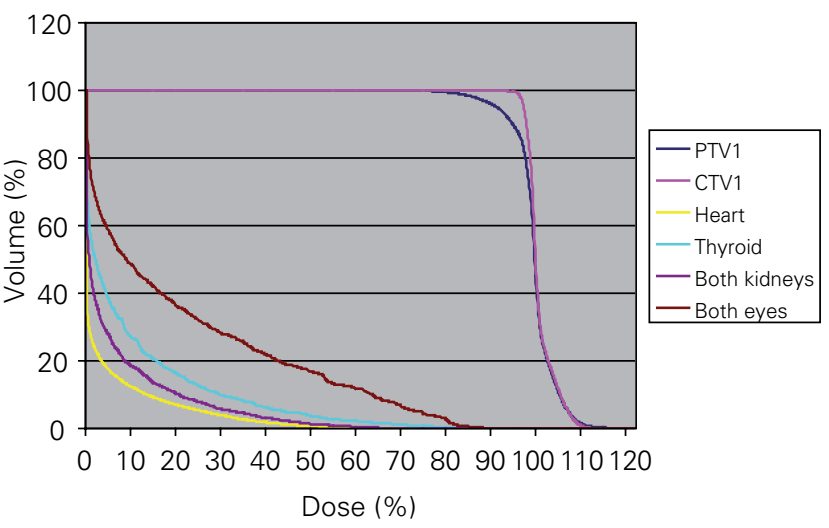


Furthermore, the posterior beam direction allowed for a precise individual conformation of dose to the frontal subarachnoid space, which is often compromised when using conventional techniques requiring face block potentially covering parts of the frontobase [4].

The sparing of organs at risk ventral to the target was in accordance with the findings published already by groups exploring passive scattered proton-beam therapy for the neuraxis [23, 27] being superior as compared to electrons and three-dimensional conformal techniques [16]. However, innovative techniques have been developed to further improve dose conformity. Bauman et al. reported on the potential advantage of tomotherapy for craniospinal treatment [2]. However, no clinical experiences were provided.

\section{Conclusion}

Spot-scanning proton therapy for the craniospinal volume has advantages regarding the ventral dose distribution and the individual coverage of the frontal subarachnoid space. Furthermore, the technique is less fragile for hot or cold spots as compared to techniques with divergent beams, because the patching of multiple fields can be avoided. Therefore, the risk for recurrences as well as for secondary cancer is potentially reduced. Unfortunately, the brain constitutes the target volume of any CSI and cannot be spared. Therefore, any radiotherapy of the complete CNS will carry the risk of brain disorders and should be administered only when indispensable for cure.

\section{References}

1. Anderson NE. Late complications in childhood central nervous system tumour survivors. Curr Opin Neurol 2003;16:677-83.

2. Bauman G, Yartsev S, Coad T, et al. Helical tomotherapy for craniospinal radiation. Br J Radiol 2005;78:548-52.

3. Bolling $T$, Schuck $A$, Rube $C$, et al. [Therapy-associated late effects after irradiation of malignant diseases in childhood and adolescence. Feasibility analyses of a prospective multicenter register study.] Strahlenther Onkol 2006;182:443-9.

4. Carrie C, Hoffstetter S, Gomez F, et al. Impact of targeting deviations on outcome in medulloblastoma: study of the French Society of Pediatric 0ncology (SFOP). Int J Radiat Oncol Biol Phys 1999;45:435-9.

5. Cox JD, Stetz J, Pajak TF. Toxicity criteria of the Radiation Therapy Oncology Group (RTOG) and the European Organization for Research and Treatment of Cancer (EORTC). Int J Radiat Oncol Biol Phys 1995;31:1341-6.

6. Cozzi L, Clivio A, Vanetti E, et al. Comparative planning study for proton radiotherapy of benign brain tumors. Strahlenther Onkol 2006;182:376-81.

7. Duffner PK, Cohen ME, Anderson SW, et al. Long-term effects of treatment on endocrine function in children with brain tumors. Ann Neurol 1983;14: 528-32.

8. Freeman CR, Taylor RE, Kortmann RD, et al. Radiotherapy for medulloblastoma in children: a perspective on current international clinical research efforts. Med Pediatr Oncol 2002;39:99-108.

9. Grabenbauer GG, Beck JD, Erhardt J, et al. Postoperative radiotherapy of medulloblastoma. Impact of radiation quality on treatment outcome. Am J Clin Oncol 1996:19:73-7.

10. Halperin EC. Impact of radiation technique upon the outcome of treatment for medulloblastoma. Int J Radiat Oncol Biol Phys 1996;36:233-9.
11. Hoppe-Hirsch $\mathrm{E}$, Brunet $\mathrm{L}$, Laroussinie $\mathrm{F}$, et al. Intellectual outcome in children with malignant tumors of the posterior fossa: influence of the field of irradiation and quality of surgery. Childs Nerv Syst 1995;11:340-5, discussion 345-6.

12. Kiltie AE, Lashford LS, Gattamaneni HR. Survival and late effects in medulloblastoma patients treated with craniospinal irradiation under three years old. Med Pediatr Oncol 1997;28:348-54.

13. Kirsch DG, Tarbell NJ. New technologies in radiation therapy for pediatric brain tumors: the rationale for proton radiation therapy. Pediatr Blood Cancer 2004;42:461-4.

14. Kortmann RD, Timmermann B, Kuhl J, et al. HIT '91 (prospective, co-operative study for the treatment of malignant brain tumors in childhood): accuracy and acute toxicity of the irradiation of the craniospinal axis. Results of the quality assurance program. Strahlenther Onkol 1999;175:162-9.

15. Kühl J, Kortmann RD, Urban C, et al. Hirntumorprotokoll der Arbeitsgruppe für Hirntumoren, HIT 2000 Protokoll. Eigenverlag, November 2000; Version 01.11.00.

16. Lee CT, Bilton SD, Famiglietti RM, et al. Treatment planning with protons for pediatric retinoblastoma, medulloblastoma, and pelvic sarcoma: how do protons compare with other conformal techniques? Int J Radiat Oncol Biol Phys 2005;63:362-72.

17. Levin WP, Kooy H, Loeffler JS, et al. Proton beam therapy. Br J Cancer 2005; 93:849-54.

18. Lomax AJ, Bohringer T, Bolsi A, et al. Treatment planning and verification of proton therapy using spot scanning: initial experiences. Med Phys 2004; 31:3150-7.

19. Mulhern RK, Merchant TE, Gajjar A, et al. Late neurocognitive sequelae in survivors of brain tumours in childhood. Lancet Oncol 2004;5:399-408.

20. Parker WA, Freeman CR. A simple technique for craniospinal radiotherapy in the supine position. Radiother Oncol 2006;78:217-22.

21. Pedroni E, Bacher R, Blattmann H, et al. The $200-M e V$ proton therapy project at the Paul Scherrer Institute: conceptual design and practical realization. Med Phys 1995;22:37-53.

22. Rutz HP, Lomax AJ. Donut-shaped high-dose configuration for proton beam radiation therapy. Strahlenther Onkol 2005;181:49-53.

23. St Clair WH, Adams JA, Bues M, et al. Advantage of protons compared to conventional $\mathrm{X}$-ray or IMRT in the treatment of a pediatric patient with medulloblastoma. Int J Radiat Oncol Biol Phys 2004;58:727-34.

24. Suc $E$, Kalifa $C$, Brauner $R$, et al. Brain tumours under the age of three. The price of survival. A retrospective study of 20 long-term survivors. Acta Neurochir (Wien) 1990;106:93-8.

25. Timmermann B, Schuck A, Niggli F, et al. ["Spot-scanning" proton therapy for rhabdomyosarcomas of early childhood. First experiences at PSI.] Strahlenther Onkol 2006;182:653-9.

26. Van Dyk J, Jenkin RD, Leung PM, et al. Medulloblastoma: treatment technique and radiation dosimetry. Int J Radiat Oncol Biol Phys 1977; 2:993-1005.

27. Yock TI, Tarbell NJ. Technology insight: Proton beam radiotherapy for treatment in pediatric brain tumors. Nat Clin Pract Oncol 2004;1:97-103, quiz 1 p following 111.

28. Yuh GE, Loredo LN, Yonemoto LT, et al. Reducing toxicity from craniospinal irradiation: using proton beams to treat medulloblastoma in young children. Cancer J 2004;10:386-90.

\author{
Address for Correspondence \\ Beate Timmermann, MD \\ Center for Proton Radiation Therapy \\ Paul Scherrer Institute \\ 5232 Villigen-PSI \\ Switzerland \\ Phone (+41/56) 310-3695, Fax -3515 \\ e-mail: beate.timmermann@psi.ch
}

